\title{
EL RELOJ Y LA BRÚJULA \\ ANÁLISIS DE LA NOVELA AGOSTO, DE ROMINA PAULA
}

Ellen Maria Martins de Vasconcellos é mestranda na área de literatura hispano-americana da Universidade de São Paulo - USP. Email: ellen.martins@hotmail.com

\begin{abstract}
Resumen
El objetivo de este texto es entender cómo la narradora de la novela Agosto (2009), de Romina Paula, construye el duelo por su amiga muerta con el tiempo y el espacio suspendidos aunque con marcas geográficas y generacionales. Para conseguir dar cuerda al reloj y encontrar el Norte de la brújula, también se analizará fragmentos aparentemente autónomos, en los cuales la narradora expone escenas de crímenes familiares vistos en la televisión.
\end{abstract}

\begin{abstract}
Resumo
O objetivo deste artigo é entender como a narradora do romance Agosto (2009), de Romina Paula, constrói seu luto pela amiga morta com um tempo e um espaço suspensos ainda que com marcas geográficas e geracionais. Para conseguir dar corda no relógio e encontrar o Norte da bússola, também se analisará fragmentos aparentemente autônomos, nos quais a narradora expõe cenas de crimes familiares vistos na televisão.
\end{abstract}

\section{1) Introducción}

"Um passado não reconhece o seu lugar: está sempre presente”.

Mário Quintana

Emilia es joven. Tiene sus veinte y picos de años. En los años noventa, fue una adolescente clase media, lo que significa formar parte de la generación $X$ (GARBATZKY, 2009), es decir, mucha música en la tele, en la radio, en cds, en cintas casete, miles de seriados en la televisión, películas, soup-operas, documentales, programas sensacionalistas... Una generación que no perdía nada del mundo pop porque los massmedia eran la sensación del momento.

Emilia perdió su mejor amiga, y por esa razón - entre algunas otras - se fue del sur de Argentina a la capital con su hermano, para encontrar un lugar suyo, "un espacio de pertenencia" (PAULA, 2009, p.96). Ya decía Matilde Sánchez, en El desperdicio (2007): "Las puertas de una mujer no las abre el destino, ellas deben ser sus propias porteras. Pero el destino solo se revela en las grandes ciudades". En Buenos Aires no había recuerdos, no había lugar para la adolescencia, los noventa ya habían pasado, el dolor era menos, y todo el resto también era menor. Incluso las expectativas, los sueños, la felicidad. Cuando Emilia es interrogada por la familia de Andrea sobre su vida, escribe: "Básicamente me preguntaron por mi vida en Buenos Aires (...), con lo cual hice una especie de recorte y conté solo lo bueno, filtrando mis temores, filtrándoles mis temores". (PAULA, 2009, p.36)

Cuando completaron cinco años de la muerte de Andrea, llegó el momento de la vuelta de Emilia a Esquel, en el sur del país, su proprio origen, para esparcir las cenizas con los familiares de la amiga. Un regreso que la lleva no solo a los lugares de buenos recuerdos con Andrea (que se quedó atrás) sino también a otras personas que el tiempo no trató de congelarlas: su padre, su amiga Vanina, su ex novio Julián, la familia que construyó su ex novio... y ahí Emilia se encuentra, "ni contigo ni sin ti", sin saber muy 
bien adónde quedaron sus planes, qué fue de su vida y qué hacer de ella de este momento en adelante. "No sé en qué pienso, no sé en qué estoy pensando, no sabría decirlo, no podría precisarlo, no podría. No sé en qué ando, si me preguntaran en qué ando, yo no sabría qué decir, qué responder, en qué ando. Sé que me canso". (PAULA, 2009, p.93)

La novela Agosto, de Romina Paula, parece tener una historia por todos conocida, leve, fluida, con conflictos que toda esa misma generación ya tuvo o aún tiene hoy en día. Emilia, que no sabe si vuelve a la capital donde están su hermano y su novio, o si se queda en Esquel, escenario de sus recuerdos; ella, que no sabe si está preparada para ser adulta y madre, o si prefiere seguir siendo solo hija, parece representar toda una generación, aunque no tome este papel de puerta-voz para sí (NUÑEZ, 2010), la cual más que vacilaciones, tiene dudas concretas que la paralizan en el tiempo del mientras tanto y en un espacio de tránsito. Pero el tono, el ritmo, el lenguaje y otras estrategias narrativas elegidas hacen que la escritura gane cuerpo y su lectura, relevancia.

El tiempo y el espacio, por ejemplo, pasan por cambios importantes en la escritura, a veces destacados por la colocación de adverbios, el "acá", el "allá" y el "ahora"; a veces marcados por el tiempo verbal - siempre presente, (pero en que el pasado y el futuro están, aunque no terminen de ser incorporados) - ; a veces por la suspensión de los mismos, cuando la protagonista admite que está en tránsito, "algo así como un punto medio, entre el querer evitar y el necesitar ir”. (PAULA, 2009, p.8). En este trabajo se buscará analizar cómo fue construido algunas de esas estrategias utilizadas para el desarrollo del diario/ larga carta (FONTÁN, 2009) que escribe Emilia a su amiga muerta.

Otra característica de la novela que se buscará analizar es la función de ciertos fragmentos que rompen la escritura de diario/carta, donde la narradora (Emilia) cuenta, como si fuera una periodista, relatos reales - al menos en la narrativa - que leyó en alguna revista o que vio en la televisión: asesinatos, canibalismos, crímenes familiares, "escenas autónomas que hablan del mal" (NUÑEZ, 2010). En la última parte de este trabajo, se analizará, por lo tanto, la función de estos fragmentos, aparentemente autónomos, descritos en medio de un proceso de duelo no solo por su amiga, sino también por los años noventa (GARBATZKY, 2009).

Estos índices de lo real, sacados de medios masivos de comunicación y narrados objetivamente con un otro tono de lenguaje que no el emotivo de la carta, no dejan de ser también una marca de la generación que pertenece la protagonista, ya que la cultura de la imagen atraviesa todos los campos, desde la consolidación de la televisión, y está presente incluso en las experiencias más afectivas. Eso se comprueba hasta en las escenas más personales del libro, como cuando Emilia se encuentra por primera vez con su ex novio, y ella narra el reencuentro y sus reacciones de acuerdo a la secuencia de canciones de la banda "The Police" que reproduce en el bar. 


\section{2) El tiempo y el espacio}

\section{"La amistad (...) no nos permite hablar de nuestros amigos, sino solo hablarles".}

Blanchot

El libro empieza con un tiempo y espacio determinados. Emilia está en Buenos Aires, recién recibió la noticia de que se cumplió el plazo legal para la exhumación del cuerpo de Andrea (cinco años) y acepta ir a Esquel para una ceremonia con los padres de la amiga muerta que ahí viven. El segundo capítulo empieza con: "Ahora escucho ruido de ratones todo el tiempo. Y eso traduce en: quiero mudarme, quiero irme de acá" (PAULA, 2009, p.13). El "acá" corresponde a Buenos Aires, la capital de Argentina, donde la protagonista vive hace algunos años. Para la narradora, la razón por la cual los ratones solo hayan aparecido "ahora" no es casual: es para que Emilia se vaya, ahora y no antes, si no, podrían haber aparecido en cualquier otro momento - algo como un evento místico, parece. Poco después, ella presenta el "allá" y el "ahí", que son lo mismo: Esquel.

Y me recordó [Ramiro] que cuando entraron ladrones en casa, allá en Esquel, que yo también, que también en esa ocasión propuse que nos mudáramos. No me acordaba pero es cierto, fue hace mucho eso. No sólo no pude dormir la noche posterior al robo, sino muchas, muchas noches más. (...) Mi viejo sigue viviendo ahí. Supongo que las razones que yo tenía para irme eran las mismas que las de él para quedarse. (PAULA, 2009, p.15,16).

Cuando Emilia toma el camino hacia Esquel, los referentes cambian, y por un momento no es posible identificar dónde es el "allá". "Quiero poder soltar Buenos Aires para ver qué me pasa allá.” (PAULA, 2009, p.18). No es posible saber si es Buenos Aires o Esquel, pues el verbo está en el tiempo presente, lo que imposibilita determinar si está hablando de su vida en la capital o de lo que pasará en el viaje.

Emi y Andrea son amigas, o mejor dicho, fueron. Y entre amigas, hay cosas que no necesitan ser dichas o reafirmadas; las dos ya saben, compartieron momentos, historias, pactos. Por eso, hay informaciones no dichas abiertamente en su diario; porque están implícitas en estos "contratos". En ningún momento se cuenta, por ejemplo, cómo fue que Andrea murió, ni por qué circunstancia. En ningún momento es presentado a los lectores tampoco por cuál razón su cuerpo fue exhumado. "Agosto nos ignora", dice Nuñez (2010). Pero es posible deducir que Andrea se suicidó por algunas pocas frases del texto como: "Vos también me habrías mandado a la mierda, alegando que Counting Crows es una garcha y que vos lo dejaste de escuchar en el noventa y cinco. Bueno, a eso solo te puedo responder que es fácil renegar de la melancolía cuando se tiene pensado vivir tan poco". (PAULA, 2009, p.53). Solo se piensa en vivir tan poco cuando se toma la decisión de morir. 
Pero la verdad clara y abierta nunca es dicha a los lectores. Eso porque, como dice Cesar Aira, la intimidad resiste al lenguaje. "Es coextensiva al secreto, pero el secreto existe en tanto efecto y la revelación, y ésta, hecha de lenguaje, es por esencia pública" (AIRA, 2007/2008, p.3). Es decir, no es necesario hablar de cosas obvias entre dos amigas o contar un secreto que solo es guardado entre las dos, mucho menos transponerlo al papel; de esa manera, la intimidad de la amistad se disolvería. Es como contar un chisme de su amiga a ella misma: no tiene sentido. "Los íntimos se entienden por medias palabras, o mejor, sin palabras". (ibídem, p.3) Y es justamente por la amistad tan íntima de las dos, que Emilia se pone tan mal cuando llega en Esquel. En Esquel, en todo, está Andrea, está en el tiempo que vivieron y en el presente, en los lugares donde pasaron y que aún existen.

Acá no, acá vengo y estás en todo. En el frío, en la mañana, en la almohada, en tu campera, en tu mamá. Y estás afuera, en la subida, el ripio, en el asfalto y ahí donde el asfalto empieza a ser tierra casi imperceptiblemente y no se puede distinguir con claridad quién engulle a quién. (...) En la escasez de ropa sobre esa piel de adolescentes, bronceadas y expuestas junto al agua, en el agua, bajo la mirada intermitente de esos otros adolescentes a la sombra de esos álamos. En eso y en la progresión del deseo. En su realización o suspensión, en su llevada a cabo o fracaso absoluto. (...) En el querer y negarse. En la negación y el avance. En la desobediencia y el saqueo. (PAULA, 2009, p.89, 90, 91)

Como se puede notar, cuando Emilia llega en Esquel, el "acá" cambia de referente. Es donde está ella, donde está la amiga muerta, pero donde está también su ex novio, donde quedó su adolescencia, sus historias más intensas.

Desde que llegué acá, desde que empecé a acercarme al valle, (...) me vino una sensación tan potente de Julián, como si simplemente hubiera estado anestesiada, como puesta en hielo, o en sal, la sensación, todo este tiempo, (...), vi el primer sol de mañana sobre los picos, todavía no daba sobre la ruta, y sentí, qué horror, la memoria en el cuerpo, en la vista, todo, una memoria sensitiva, de sentidos, alojada ahí, la memoria se ríe de planes, de decisiones. (PAULA, 2009, p.26)

Por eso que Emilia pasa a sentir como si ningún lugar le fuera suyo. Ella está atrapada en un no lugar, en un no tiempo. El pasado le pega al presente y la narradora no consigue salir de este entremedio donde no es más la hija que necesita de cuidados pero tampoco es la madre, de los hijos de Julián, de los hijos de Manuel. Cuando Emilia en su diario/carta cuenta sobre la ceremonia de esparcir las cenizas, dice: "Fui tan hija ahí, con todos los adultos." (PAULA, 2009, p.57), Emilia se porta como si aún fuera la joven adolecente. "No puedo ir así, no puedo, pero tampoco me puedo quedar; ¿qué mierda voy a hacer?" (ibídem, p.82). Emilia entonces se queda como que flotando en el aire, incompleta, esperando alguna idea brillante que se le aparezca o que alguien se la sugiera, "asaltada por una sensación de pertenecer y no pertenecer" (ARÁN, 2011), para actuar, para salir de este tiempo del mientras tanto y de este espacio de tránsito. Pero por un tiempo, es ahí donde quiere estar: en la ilusión de que así está más cerca de la amiga muerta. Días después, aún en este tiempo suspenso, confiesa: "La gente trabaja, yo no. Yo miro por la ventana.” (PAULA, 2009, p.93) Ella aún está sin respuestas o dirección. 
No desempleada o de vacaciones, sino en otra posición, sin nombre, en un presente estático y extraño. Por eso también, ve la televisión: "Lo único que te salva es la ficción" (ibídem, p.94).

Muchas veces el diario vuelve a lo que sucede en Buenos Aires, que es donde está su hermano que desde allá le cuenta por teléfono cómo anda el tema del gato y del roedor. El roedor que aparece en los sueños de la protagonista desde el primer capítulo también aparece materializado en su casa, enrareciendo todo el espacio hasta tornarlo inhabitable para Emilia, que encuentra como única solución irse. Desde Esquel, sigue teniendo noticias de cómo se soluciona el asunto incómodo, pero que, por la distancia, gana trazos de ficción tal cual otros temas perturbadores que ve en la tele. Cuando escribe en el diario sobre los eventos de Buenos Aires - la instalación cómoda del gato que nunca pensó en cazar el roedor, la búsqueda de informaciones sobre venenos y la muerte asquerosa del "mazacote de pelos" debajo de la pileta, Emilia escribe en un ritmo ligero, sin puntos, como si fuera un juego de preguntas y respuestas donde no hay tiempo para pensar: "Aparentemente no llegaba a ser una rata, pero tampoco tenía la escuetez de una lauchita: era un claro ratón, entre marrón y gris, común, según Ramiro; un ratón estándar, agrego yo y Ramiro dice que sí, triunfante. Un horror. (...)" (PAULA, 2009, p.61)

Ya acercándose del final, la narradora empieza a darse cuenta que no es en Esquel donde debe quedarse y toma la decisión de volver a la capital y volver también a ser una. Además, entiende que la amiga está muerta en cualquier parte, en Buenos Aires, en Esquel, ella ya no está en ningún lado. Con el proceso del duelo por su amiga y por este tiempo que ya pasó, Emilia pasa a querer algo. Y al volver a pensar en Buenos Aires como un hogar, vuelve a mezclar los pronombres demostrativos, para por fin definir donde es el "allá" y el "acá" de la narradora:

Pensé más seriamente o con más frialdad, sin tanta tontera, en Manuel y en lo que teníamos, en lo que tenemos y decidí, tomé una decisión. Que no quiero perderlo, que eso, esto, es mi vida ahora (...) Porque es eso, porque no hay en realidad, nada otro para mí, nada esperándome. Acá quiero decir, eso, acá. Allá sí, en Buenos Aires. (...) Además tu muerte no hace al lugar, todo lo contrario, estás muerta en todas partes. Así que eso, me digo que no es querer huir, todo lo contrario, es combatir el querer quedarse. (PAULA, 2009, p.96)

Más adelante, Emilia aunque ya sepa adónde ir y a quién volver, con la invitación de Julián de hacer un viajecito y tomar el colectivo a Buenos Aires en otra ciudad del Sur, vuelve a este estado en el cual el tiempo y el espacio están interrumpidos. Aunque haya tomado la decisión de regresar con su novio, al encontrar con su ex, los sentimientos se confunden y ella torna a perderse. "Lo peor es que ahora ya ni siquiera puedo darme cuenta de qué es mejor, qué es lo mejor, de qué hubiese sido mejor, si irme, si quedarme, si sí él, si no él, si Manuel, si qué. Probablemente dé lo mismo." (PAULA, 2009, p.131) 
Esta vez la acompaña Julián a este "aquí y ahora, claramente, el mejor lugar para estar en el mundo" (PAULA, 2009, p.124). Julián, que se muestra todo el tiempo responsable y sin ninguna duda de donde es y adónde va, le autoriza a Emilia a llevarlo a este "no tiempo" y "no lugar", por un tiempo: "Ahora estamos sostenidos en el tiempo acá sobre esta ruta, no estamos en él, esta línea que trazamos con el auto está fuera del plan, fuera de la red, del entramado. Venimos de y vamos hacia pero acá no hay, este camino no existe, somos nosotros suspendidos" (ibídem, p.143).

Hasta que Emilia parece entender: "Es éste y no otro el último momento para huir pero no lo hacemos. (...) Prefiero creer que por alguna razón merezco o merecemos este olor, estos tonos de falso pastel" (PAULA, 2009, p.147). Enredada en el tono patético que tiene el cotidiano en cualquier lado, la narradora vuelve a percibir el tiempo y el espacio del presente. Se acabó finalmente el viaje en el tiempo.

De repente, después de una borrachera y de una charla honesta con su ex novio, el "allá" ya no es Buenos Aires o Esquel: Emilia cae en sí y se despide de la amiga. "Es la borrachera, es el duelo" (PAULA, 2009, p. 156). El "allá" pasa a ser donde está la amiga, dice "ahí abajo" en la página 154, debajo de la tierra, dice "Yo acá y del otro lado vos. Llevo eso enorme entre mis brazos y no veo qué, y así abrazada a lo que no es, me quedo, pegada a un núcleo de algo que define un acá y otro acá, que no se ven ni se tocan, no más." (ibídem, p.167) Acá es el lado de la vida, y aunque pueda ser Buenos Aires o Esquel, los adverbios de lugar están definidos y ya no se tocan.

El pasado y la memoria - mezcla de oro y horror, huecos, construcciones de relatos, silencio e imaginación - encontraron su lugar: el cuaderno donde escribió el diario/ esta carta de despedida. Y aunque Andrea esté muerta, en la escritura sigue, "eso enorme entre mis brazos", en la memoria de Emilia, Andrea sigue existiendo. "O que se escreve, se enraíza", dice Blanchot (2005, p.270).

Y tenemos que aprender que cuando la palabra se calla, una palabra que, a lo largo de los años, se ofreció a una <exigencia sin miramientos>, no es solo esta palabra la que ha cesado, es el silencio que ella hizo posible, y desde el que volvía, según una invisible pendiente, hacia la inquietud del tiempo. (BLANCHOT, 1976, p.266, 267)

Tampoco existe memoria sin olvido. Sí, es en la escritura que se reconstruye el pasado, pero no se puede construir lo que ya no existe. Es "en vano que pretendemos mantener, con nuestras palabras, con nuestros escritos, lo que se ausenta" (BLANCHOT, 1976, p.264). Es decir, si es pasado, ya no existe como presente; hay que dar continuidad al tiempo, mantener vivo lo que aún se tiene. Emilia al escribir mantiene a su amiga viva.

Para Andreas Huyssen, el miedo al futuro es la causa de que la cultura de la memoria esté tan fuerte en la contemporaneidad. Con la percepción de que el futuro es incierto y puede ser aterrador, las personas se pegan a lo que tienen seguro, controlable: nada mejor que el pasado. En la memoria, los objetos, los amigos, las fronteras 
culturales, los símbolos de cada generación ya están bien delineados, y ya son permanentes sus relaciones con el flujo del tiempo. En el futuro, nada es particular todavía, y la sensación de incertidumbre paraliza. "Quanto mais rápido somos empurrados para o futuro global que não nos inspira confiança, mais forte é o nosso desejo de ir mais devagar e mais nos voltarmos para a memória em busca de conforto." (HUYSSEN, 2004, p.32).

Sin embargo, no es posible olvidar que una mirada sobre cualquier que sea la imagen del pasado no deja de ser una interpretación personal, es decir, de cada viviente sobre la tierra. La memoria no es del otro que ya no está, que se murió, sino de uno mismo, el que se recuerda del pasado al mismo tiempo sigue viviendo y teniendo nuevas historias. Y solo así, es posible salir en el presente en búsqueda de un futuro; así, todo junto y al mismo tiempo. Es la única forma.

Yo por mi parte lloro todo el viaje de vuelta y ése es recién el principio del fin porque por lo menos todavía estoy en tránsito, lo peor viene después, cuando tengo que recuperar mi vida, tomar el toro por las astas, reconstruir mi casa, mi relación con Manuel, (...), y que nunca voy a terminar de saber exactamente qué quiero y que tal vez me esté equivocando siempre y entonces ni irse ni quedarse ni nada, ni estar, ni estar. (PAULA, 2009, p.161)

\section{3) La televisión}

"Qué horror, qué espanto, y yo escondida detrás del yuyo, qué patético, la historia de mi vida: la gente forma familias mientras yo me oculto detrás de un arbusto." (PAULA, 2009, p.30) Emilia no solo se oculta, hay otro movimiento en esta escena: ella espía, ella observa el otro, lo analiza. En todos los relatos en Agosto hay un cierto horror, una tendencia a romper lo romántico y el cliché del escenario. Nada es como una escena clásica de película de Hollywood, donde los actores nacieron uno para el otro y hay siempre un final feliz (y aburrido). En la vida real, es decir, en la vida de Emilia, lo bonito se mezcla con lo feo, lo heroico con lo cómico, lo idealizado con lo patético. Ese quiebre de expectativa es encontrado desde la escena quizás más cursi de la novela hasta en las imágenes que ve la protagonista en la televisión.

Suena Every Breath you take, hay varios puntos de contacto de mi cuerpo con el suyo, voy relajándome, dejando/apoyando mi peso sobre esos puntos, pasándoselo todo a él, el peso, inhalando su olor, hay de todo ahí, es él y a la vez hay un par de texturas nuevas, algo de niño, vómito o alguna otra cosa, y olor a comida, un poco de olor a comida también. (PAULA, 2009, p.68)

Emilia cuando llega a Esquel para la ceremonia de esparcimiento de las cenizas, antes de sentirse lista para rever las personas que se quedaron en la ciudad, pasa algunos días sin salir de la casa de Andrea, leyendo lo que encuentra y viendo programas de televisión; y a causa de eso, en medio de su escritura, describe además de sueños raros, incluso muy violentos, historias de familias disfuncionales y relatos de crímenes verdaderamente siniestros. Entre lo que escribe y lo que calla queda un sentimiento de 
desprotección, y se puede percibir en todas esas historias una amenaza y un movimiento: las relaciones sociales tarde o temprano culminan en tragedias. Y no solo en esos relatos aparentemente independientes: en toda y cualquier historia, el horror se coloca afuera, así como la verdad.

Como ya tratado, la protagonista pertenece a una generación muy marcada. Se puede percibir por la forma de hablar, por ciertas jergas, por los dilemas que pasan e también por lo que ve y escucha. Es una generación vinculada con los medios, y sometida a estímulos que diariamente modelan el imaginario y la subjetividad. Así, crece insatisfecha (GARBATZKY, 2009) y ve la vida de una forma mucho menos excitante (CAPELLI, 2010). "Le dije que no tenía mucho tiempo en realidad, que el combo facultad-trabajo-novio no me dejaba mucho tiempo para mí". (PAULA, 2009, p.51).

Y es justamente por esa insatisfacción tenaz del deseo, que la generación de los noventa representa la sociedad de consumo y del entretenimiento (GONZÁLEZ, 2012). Elementos en la novela de Romina Paula que corroboran esa afirmación están desde el episodio de las zapatillas coloradas (PAULA, 2009, p.29), hasta los títulos de películas, los grupos musicales citados, la indumentaria, y otras referencias al mundo pop: "Así termino el día, la larga jornada de sobresaltos: llorando y comiendo sándwich, como Chihiro pero más triste, porque no es por mi mamá y mi papá convertidos en cerdos que lloro, sino por mí, que ya no soy nada/que soy una imbécil.” (ibídem, p.77). En este fragmento cita el personaje de la película El viaje de Chihiro, del director Hayao Miyazaki, de 2002.

Otras piezas de la cultura de masas que componen el libro son esas noticias escritas o transmitidas por la televisión que Emilia ve y prácticamente no se sorprende, describiéndolas con una frialdad periodística. Estas escenas "refieren a episodios truculentos de la vida real que la narradora cuenta como si dijera: todo esto pasa, incluso esta violencia condensada a la que pongo afuera para que no me envenene." (NUÑEZ, 2010). Son escenas de la vida privada pasadas a la vida pública, por el papel o la pantalla, "donde todos somos pares y nos mimetizamos. El idioma de los derrotados es atractivo e igualador." (PUEBLA, 2014) La narradora Emilia también confirma esta sentencia: "Lo mismo que me atrae es lo que me deprime, ése es el dilema" (PAULA, 2009, p.36)

Son cuatro relatos. El primer está en la página 32 y la narradora después de una serie de preguntas sobre la educación, la inhibición y el miedo - preguntas intencionalmente sin respuestas - , cita a un artículo cuyo tema es el nivel de maldad que las personas tienen o pueden llegar a tener: una escala que va del uno al veintidós. Casi todo el cuento es elaborado con períodos simples para que el ritmo de lectura se mantenga acelerado de la primera a la última frase. Para encerrar el fragmento, Emilia se pregunta cuál será el nivel de maldad que tiene una persona que decide morirse. Esa es la palabra elegida para no usar matarse. No hay como no relacionar la pregunta que 
se hace al gesto que tuvo su amiga cinco años antes: matarse. No es ostensible, porque el tono que utiliza es sutil, pero hay una ligera burla en este tipo de interrogante, como una sugerencia de reflexión.

El segundo relato, en la página 54, otra vez es sugerido el asunto de matarse a si propio, pero con otra perspectiva. La historia aquí es de una familia que come a uno de sus miembros, la mujer de un hijo. La secuencia de varias preguntas una tras otra también se repite. En este relato, las preguntas, también retóricas, parecen ser transcriptas tal cual fueron escuchadas. “¿El sadismo se extendería a todos? ¿Su marido la defendería o sería el primero en someterla? ¿Ella habría podido huir o pedir ayuda antes el encierro absoluto?" (PAULA, 2009, p.55) Parecen salidas de la boca de un presentador de programa sensacionalista, que interpela al espectador, que obviamente, por estar del otro lado de la pantalla, no es escuchado. Al final del relato, la narradora propone una comparación entre la familia caníbal y una familia autótrofa de hámsteres. Otra sugerencia de reflexión: el auto-destrucción consciente de la familia.

La tercera historia empieza en la página 78 y es la más detallada. Otra situación extranjera. La anterior era inglesa, esta estadounidense. Es sobre dos hermanas y el novio de una de ellas, un estuprador, torturador y asesino. Una de las hermanas, la menor, es asesinada y la otra, después de años de abuso, decide denunciarlo y confesar todo lo que sabe. El lenguaje típico de un documental de tragedias familiares es expuesto: períodos simples, descripciones frase a frase de lo que gana imagen y color en la televisión. Algunas frases empiezan con la conjunción "Y", es decir, la narradora opta por escribir frases cortas pero concatenadas. "Ella dice que no lo soporta más, que quiere que tenga su merecido. Y empieza a confesar: que sí, que ella también era parte de las rondas de violación y tortura. Y no solo como cómplice (...) Y hay más..." (PAULA, 2009, p.79). Como componente típico de esas crónicas, surgen las preguntas retóricas otra vez: “¿No es peor la delación? ¿No deberían aumentar su pena por eso mismo?" En el último párrafo, la narradora (Emilia) interviene en la historia con su opinión: cuenta sobre la exhumación del cadáver de la hermana menor y admite que es truculento lo que la hermana viva hizo: sexo oral en su novio vestida con la ropa de la muerta mientras él la filmaba. Y ahí termina la crónica. La exhumación del cadáver sería un elemento común de esta historia a lo que presenció Emilia. El vestirse con la ropa de la muerta también. "Tu campera, la nuestra” (ibídem, p. 119).

El último fragmento presenta la crónica de una pareja de ancianos cuyo marido mata a la mujer y la incinera en un horno de fundición en su trabajo. Después se trasviste de ella y da unos paseos donde es visto por las cameras de la ciudad sacando dinero, como si fuera ella. Enseguida, escribe una carta suicida para la familia. La hija no se convence, y ruega a la policía que sigan con la investigación. Se descubre que la carta suicida fue sellada con la saliva del marido, y él es descubierto asesino. En este relato no hay preguntas de la narradora indagando el lector/espectador. Pero como en los dos primeros, las frases finales sugieren temas de reflexión. "Curioso que con ese 
nivel de ficción encima, omitiera el detalle de la saliva en el sobre. Otra vez aquello de la fagocitación, de la deglución." (PAULA, 2009, p.103). Cierta obsesión con comerse a sí mismo o más bien, a alguien de la familia.

Emilia narra estos cuatro fragmentos indiferente, indiferentes. Es decir, narra el horror como si narrara una cena con los padres de su amiga. Solo que en un ritmo más ligero. En todos los casos, el horror tiene una cierta ironía. Es "exhibido" con perspicacia: nada está puesto fortuitamente, hay una razón de ser. Emilia describe un asesino serial como si fuera un actor o un personaje de película: "Uno de los ejemplos era Ted Bundy, muy sonriente él, muy bronceado y comprador..." (PAULA, 2009, p.33), caracteriza las víctimas del novio del tercer relato como rubiecitas tontas; y la anciana muerta por el marido en la última historia como una vieja de peluca y dientes nuevos. Parecen todos personajes típicos. Pero la ironía mayor está en la última frase del último relato: "Todo queda en familia" (Ídem, p.103) Esta expresión, además de muy conocida, es verdadera y se relaciona con lo que dijo Cesar Aira sobre lo íntimo. Hay un "entre nosotros" que no permite que lo íntimo se torne público, son los secretos de amigas, de amantes, de familia, incluso a veces de una ciudad. La intimidad se queda cerrada ahí en ese núcleo, "en la reducción del plural al singular (...), donde no es necesario hablar" (AIRA, 2007/2008). Emilia y Andrea tienen sus secretos. Y estos morirán con ellas. De ese modo, la narradora liga la televisión con lo íntimo, liga las historias transmitidas en la tele o publicadas en revistas con las experiencias más afectivas. Así, esas nuevas formas de circulación de la palabra y de experiencias sensibles exhibidas en los medios se mezclan con lo vivido, y lo que es realidad y ficción se disuelven porque pasa a integrar y ser reconocido como parte de la identidad de uno.

En la introducción de este artículo, estos cuatro relatos fueron clasificados como "aparentemente autónomos". Eso porque a pesar de no tratar de la vida y de los problemas que pasa la protagonista personalmente, y a pesar de no ser narrado en segunda persona como la carta - que les da un carácter independiente -, estos relatos tienen mucho en común con todo el resto: la muerte como sombra (CAPELLI, 2010), lo trágico como destino, y la fragilidad que es construida cualquier relación entre dos o más personas. Estos relatos violentos son rescatados porque forman parte de la red de imágenes de la realidad que Emilia está en contacto. Además, su vida, como ya se ha dicho, también está pasando por un instante atemporal o bien podría pasar por un relato de ficción, como de hecho, es la literatura. Ya no hay motivo para diferenciarlos. Ya no se trata más de ser un espectador pasivo (RANCIÈRE, 2010): Emilia tiene una relación con estos relatos que ultrapasa la lógica contemplativa y quiebra el abismo entre la apariencia y la esencia. Ella toma los relatos para sí, así como todas las historias que se acuerda, las películas y seriados que vio con su amiga que ya no vive, las canciones que escuchó. "Vos también me habrías mandado a la mierda, alegando que Counting Crows es una garcha y que vos lo dejaste de escuchar en el noventa y cinco". (PAULA, 2009, p.53) 
La crueldad está en todas partes, y no hay como dejar de sentir pánico mientras uno está vivo. Al mismo tiempo, esas imágenes atroces transpuestas al papel hace que la narradora también tome cierta distancia de ellas, así como toma distancia de su vida en Buenos Aires y de lo que ve detrás de un arbusto: expulsa de alguna manera lo trágico de su pensamiento. Al ver las cosas desde "allá", o sea, desde su cuaderno, Emilia ya no las tiene para sí, están exteriorizadas. Como su sueño en que corta en pedazos un muchacho y los guarda en una bolsa (PAULA, 2009, p.132). En el sueño, ella intenta pensar en alguna forma de deshacerse del cuerpo, y al final, lo deja en un pasillo con otras cosas que están tiradas ahí. Quizás sea lo mismo con esas imágenes violentas que ve en la tele o lee en un reportaje: las transcribe para poder abandonarlas. Para sacar lo horror también de uno mismo. Una.

\section{4) Conclusiones}

\section{"Assegurar o passado não é uma tarefa menos arriscada do que assegurar o futuro".}

\section{Andreas Huyssen}

Los punteros del reloj no paran, pero se permite suspenderlos en un viaje. Un viaje, para esparcir cenizas, esparcir pensamientos, para ver el "acá" desde el otro "acá", para crecer un poco, desde lejos, desde "allá". La interrupción del tiempo en un viaje sirve para pensar si uno aún está de acuerdo con su vida actual, si está contento con el lugar donde vive, si aún se siente vivo... Emilia cumple este lugar de viajera, aunque escriba en su cuaderno: "esto no es un viaje” (PAULA, 2009, p.82).

Pero es justamente en los viajes también que se autoriza uno a ser otro. Bauman dice: "Pensamos en la identidad cuando no estamos seguros del lugar al que pertenecemos. (...) Identidad es un nombre dado a la búsqueda de salida de esa incertidumbre". (BAUMAN, 2003). Siendo otro, o sea, tomando distancia de lo que uno piensa que es, es posible explorar lo que uno tiene y lo que a uno le falta. Es difícil. A Emilia le fue concedido ese derecho de viajar y suspender el tiempo, para procesar un duelo, para ver "desde allá". Y eso es algo que (también) le atrae al mismo tiempo que le da miedo: "Me desestabiliza o por lo menos desconcierta su cuerpo - de hecho - tan lejos del mío. Ya perdí la costumbre, es eso, ya la perdí. Perdí la costumbre de ser uno. Una”. (PAULA, 2009, p.19)

Luego, al acostumbrarse con la distancia, ya no lo extraña (a Manuel), sino que se entusiasma (un poco) con la posibilidad de ser otra: "Ramiro me recordaría que me pasa siempre lo mismo cuando me voy de viaje, que no quiero volver, que siempre me fascino con otra vida, que me quedo enganchada con todas esas otras que soy cuando estoy lejos" (PAULA, 2009, p.81) 
Pero ella vuelve. Al final del viaje, después del proceso de duelo y de tanto llanto, Emilia va a volver. $\mathrm{O}$ al menos, sentada en la terminal de bus, esperando que el colectivo la lleve a Buenos Aires, quiere volver: volver a ser una, a ser "lo más parecido a la mejor versión de uno". (PAULA, 2009, p.167) Ese deseo, que es el que cierra el libro, da cierta esperanza a los viajes de duelo. Uno puede no cambiar, pero al menos, entierra algunos fantasmas y descubre ciertas verdades. En los programas que Emilia ve en la televisión ocurre lo mismo. Los muertos pasan a formar parte de los vivos, (algunos literalmente), y la vida sigue.

Así como en un viaje, donde además del tiempo suspendido, es construida "una relación ficticia entre mirada y paisaje" (AUGÉ, 2000, p.86), un espectador que ve televisión también tiene el tiempo interrumpido y erige una relación ilusoria con lo que está del otro lado de su pantalla: lo que ve le pertenece. Aquello que le parece ajeno, en realidad, no lo es. A pesar de todo, de tanta pérdida, de tanta historia ficcional (y no), de tanta angustia que encarnó sobre la narradora en ambas situaciones - en el viaje y en la tele - Emilia termina real, un poco rota, pero sana, y sabiendo que "a esta altura algo de [la calle] Bogotá me pertenece" (PAULA, 2009, p.116). Y aunque parezca insuficiente, para aquellos que siguen suspendidos en no lugares y en no tiempos - y que no son pocos - ya es una victoria sentirse vivos. Una protagonista verosímil en un drama posible, con artificios justificables y un lenguaje condecente: Agosto tiene una escritura potente. Y qué alivio que llegó septiembre.

\section{Referencias}

AIRA, Cesar. "La intimidad". Boletín/ 13-14. Rosario: Centro de Estudios de Teoría y Crítica Literaria, Diciembre 2007/ abril 2008. Disponible en: http://www.celarg.org/int/arch_publi/ aira_13_14.pdf Acceso en: 26/03/14.

ARÁN, Rosário. "El receptor ausente". In: Libros y literatura. Reseña de Agosto. 2009. Disponible en: http://www.editorialentropia.com.ar/agosto.htm Acceso en: 26/03/14.

AUGÉ, Marc. Los no lugares, Espacios del anonimato: Una antropología de la sobremodernidad. Barcelona: Gedisa Editorial, 2000.

BAUMAN, Zigmunt. De peregrino a turista o uma breve historia de la identidad. In: Hall, Stuart. Cuestiones de identidad cultural. Buenos Aires: Amorrortu, 2003.

BLANCHOT, Maurice. O diário íntimo e a narrativa. In: O livro por vir. São Paulo: Martins Fontes, 2005.

. La amistad. In: La amistad. Madrid: Editorial Trotta, 1976. 
CAPELLI, Matías. “Confesiones de invierno”. In: Los Inrockuptibles. Reseña de Agosto. 2010. Disponible en: http://www.editorialentropia.com.ar/agosto.htm Acceso en: $26 / 03 / 14$.

FONTÁN, Brenda. "Ganas y desganas”. In: Revista Veintitrés. Reseña de Agosto. 2009. Disponible en: http://www.editorialentropia.com.ar/agosto.htm Acceso en: 26/03/14.

GARBATSKY, Irina. "Una chica de los noventa". In: La Capital. Reseña de Agosto. 2009. Disponible en: http://www.editorialentropia.com.ar/agosto.htm Acceso en: 26/03/14.

GONZÁLEZ, Manuel. "Generación X: la revolución dormida”. In: Revista de Letras. 2012. Disponible en: http://revistadeletras.net/generacion-X-la-revolucion-dormida/ Acceso en: 26/03/14.

HUYSSEN, Andreas. Seduzidos pela memória: arquitetura, monumentos, mídia. Rio de Janeiro: Aeroplano, 2004.

NUÑEZ, Jorgelina. "Todas las despedidas que nos habitan". In: Revista $\tilde{\mathbf{N}}$. Reseña de Agosto. 2010. Disponible en: http://www.editorialentropia.com.ar/agosto.htm Acceso en: $26 / 03 / 14$.

PAULA, Romina. Agosto. Buenos Aires: Entropía, 2009.

PUEBLA, Paula. "El feminismo caníbal de Malena Pichot”. In: Revista Paco II.

Disponible en: http://revistapaco.com.ar/2014/01/16/7843/ Acceso en: 16/01/14.

RANCIÈRE, Jacques. El espectador emancipado. Pontevedra: EllagoEnsayo, 2010.

SANCHÉZ, Matilde. El desperdício. Buenos Aires: Alfaguara, 2007. 